\title{
RAZOABILIDADE E TEORIA DA RESERVA DO POSSÍVEL COMO FUNDAMENTOS PARA O CONTROLE JURISDICIONAL DE POLÍTICAS PÚBLICAS: UMA ANÁLISE A PARTIR DA TEORIA DO DISCURSO1
}

\author{
REASONABLENESS AND RESOURCE LIMITATION THEORY AS FOUNDATION FOR JUDICIAL \\ REVIEW OF PUBLIC POLICIES: AN ANALYSIS FROM THE DISCOURSE THEORY
}

Mônia Clarissa Hennig Leal" Fernando Roberto Schnorr Alves"*

\begin{abstract}
Resumo: No presente trabalho abordou-se a importância da teoria do discurso para a construção de decisões judiciais que, ao encontrar os espaços semânticos que possibilitam a discussão por meio da argumentação jurídica, não implica a mera tarefa de subsunção. Assim, nesses casos, cabe ao julgador não somente a tarefa de decidir, mas de fundamentar sua decisão, sempre prezando por um procedimento e uma argumentação racional. Dessa forma, diante do caso específico da razoabilidade, originalmente associada à teoria alemã da reserva do possível, com o presente artigo visou-se a uma abordagem voltada à construção dessa decisão, desde o procedimento do discurso jurídico até a aplicação da ponderação para a solução do caso concreto, no desempenho da tarefa judicial de assegurar os direitos fundamentais. Buscou-se, assim, quais critérios devem (ou deveriam) ser utilizados na fundamentação da decisão judicial quando da
\end{abstract}

aplicação, em especial, do mencionado critério da razoabilidade. Para o desenvolvimento do estudo, adotou-se o método de abordagem dedutivo. Além disso, como método de procedimento se aplicou o monográfico. Por fim, os resultados apresentados evidenciam que a argumentação jurídica e o procedimento da ponderação, quando devidamente demonstrados pela decisão, são capazes de afastar as críticas de subjetividade e a sensação de insegurança jurídica nos casos de espaços semânticos ou textura aberta das normas, bem como se concluiu que o critério de razoabilidade é tão significativo como o critério orçamentário da teoria da reserva do possível.

Palavras-chave: Razoabilidade. Reserva do possível. Ponderação. Teoria do discurso e da argumentação jurídica. Controle jurisdicional de políticas públicas.

\footnotetext{
Pós-Doutora na Ruprecht-Karls Universität Heidelberg (Alemanha); Doutora em Direito pela Universidade do Vale do Rio dos Sinos (com pesquisas realizadas junto à Ruprecht-Karls Universität Heidelberg, na Alemanha); Professora do Programa de Pós-Graduação em Direito (Mestrado e Doutorado) na Universidade de Santa Cruz do Sul; moniah@unisc.br

"* Mestre em Direitos Sociais e Políticas Públicas na linha de pesquisa Constitucionalismo Contemporâneo pela Universidade de Santa Cruz do Sul; Graduado em Direito pela Universidade de Santa Cruz do Sul; Advogado; Rua da Garoupa, s/n, Capão da Canoa - RS, 95555-000; fernandorsalves@hotmail.com

1 Este artigo é resultante das atividades do projeto de pesquisa Dever de proteção (Schutzpflicht) e proibição de proteção insuficiente (Untermassverbot) como critérios para o controle jurisdicional (qualitativo) de Políticas Públicas: possibilidades teóricas e análise crítica de sua utilização pelo Supremo Tribunal Federal e pela Corte Interamericana de Direitos Humanos, financiado pelo CNPq pela FAPERGS, onde os autores atuam na condição de coordenadora e de participante, respectivamente. A pesquisa é vinculada ao Grupo de Pesquisa Jurisdição Constitucional aberta (CNPq) e desenvolvida junto ao Centro Integrado de Estudos e Pesquisas em Políticas Públicas (financiado pelo FINEP) e ao Observatório da Jurisdição Constitucional Latino-Americana (financiado pelo FINEP), ligados ao Programa de Pós-Graduação em Direito (Mestrado e Doutorado) da Universidade de Santa Cruz do Sul.
} 


\begin{abstract}
In this paper one approached the importance of discourse theory for the construction of judicial decisions, which, finding the semantic spaces which allow the discussion by juridical argumentation, does not imply the simple task of subsumption. Thus, in these cases, it is up to the judge not only the task of deciding, but giving reasons for his/her choice, always focusing on a rational procedure and argument. Therefore, before the specific case of the criterion of reasonableness referred originally in German theory of the resource limitation, with this paper one aimed an approach oriented to the construction of this decision, from the procedure of juridical discourse to the application of the weighting legal for the solution of the case approach, on the performance of judicial task of ensuring fundamental rights. It was sought, thus, which criteria must (or should) be used in the reasoning of the judgment, in particular, when applying the aforementioned criteria of reasonableness. For the development of the study, one adopted the deductive method of approach. Moreover, as a procedure method, it was applied the monograph one. Finally, the results show that the legal arguments and the weighting procedure, when properly demonstrated by the decision, are able to deflect criticism of subjectivity and the feeling of legal uncertainty in cases of semantic spaces or open texture of standards, as well as it was concluded that the criterion of reasonableness can be as significant as the budget criterion of the theory of resource limitation.
\end{abstract} Keywords: Reasonableness. Resource limitation. Balancing. Discourse theory and juridical argumentation. Judicial review of public policies.

\title{
Introdução
}

Para a construção de uma decisão, cabe ao julgador um processo não apenas de escolha, mas também de fundamentação. Quem julga tem o compromisso de proferir uma decisão coerente e, principalmente, consubstanciada com o ordenamento jurídico no qual está inserida. Ocorre que quem profere uma decisão não poderá se valer somente da subsunção, sendo necessário interpretar os dispositivos do ordenamento jurídico para buscar a norma do caso concreto, ocorrendo, assim, uma abertura para a argumentação jurídica e, consequentemente, para a teoria do discurso. Ou seja, o julgador deve fazer o possível para aplicar a norma sem criar interpretações extensivas ou criativas, pois esta é uma operação lógica e que busca a aplicação do raciocínio. Porém, ela depende ao mesmo tempo da construção das premissas, em que ocorre a abertura para a argumentação jurídica.

Dessa forma, quando houver uma decisão que versa sobre a aplicabilidade da teoria da reserva do possível, para proferir uma decisão procedente ou improcedente, cabe ao magistrado não apenas analisar os aspectos que essa teoria desenvolve, mas também fundamentar a sua decisão. Ao desempenhar tal tarefa, compete a ele demonstrar o processo utilizado quando da ponderação dos argumentos pró e contra a condenação do Estado, como, por exemplo, no caso de uma condenação à prestação de uma política pública para a garantia de um direito fundamental.

Ressalta-se que a teoria da reserva do possível, como exemplo de aplicação para o presente artigo, aborda não somente o cunho financeiro, qual seja, os limites do orçamento do Erário, como o critério de razoabilidade ${ }^{2}$ da prestação que é exigida do Estado. Nesse campo, há extensa margem de interpretação para o magistrado, o que exige deste maior preocupação no momento de fundamentar

\footnotetext{
2 Embora exista divergência doutrinária entre os diferentes conceitos, em razão de não ser o objeto de estudo do presente trabalho, adotar-se-á o critério de razoabilidade como sinônimo de proporcionalidade. Como exemplo de autores que entendem pela distinção entre ambos conceitos, citam Silva (2002, p. 28) e Ávila (1999, p. 173); em contraposição, Camargo (2005) aponta que a própria jurisprudência do STF, em algumas oportunidades, demonstrou entender ambos princípios como sinônimos.
} 
a sua decisão, esclarecendo os pontos da argumentação que levaram à conclusão de que a sua decisão é a mais adequada para o caso concreto.

Dessa forma, com o presente artigo visou-se a uma abordagem voltada à construção da decisão, desde o procedimento do discurso jurídico até a aplicação da ponderação para a solução do caso concreto. Para o desenvolvimento do estudo, adotou-se o método de abordagem dedutivo. Além disso, como método de procedimento se aplica o monográfico. Buscou-se, assim, identificar os critérios que devem (ou deveriam) ser utilizados na fundamentação da decisão judicial quando da aplicação, em especial, do critério da razoabilidade associado à teoria, de origem alemã, da reserva do possível.

\section{A teoria da reserva do possível}

Antes de se entrar na questão da construção propriamente dita da decisão que envolve o critério de razoabilidade da teoria da reserva do possível, cabe explicar, de forma introdutória, a sua aplicação. Desse modo, impende citar que a referida teoria conquistou espaço no controle jurisdicional no que se refere, principalmente, à concretização dos direitos fundamentais sociais, embora no Brasil seja amplamente difundido apenas o seu caráter de reserva orçamentária, relativizando-se, na maioria das vezes, o aspecto da razoabilidade da prestação requerida.

Mesmo diante de todo o conteúdo já positivado na área dos supracitados direitos, ainda se encontra dificuldade em implementar aquilo que o Texto Constitucional refere. Por se tratarem de normas de cunho programático ${ }^{3}$ (no sentido de que são dependentes de prestações tanto fáticas quanto normativas) e diante da discricionariedade política ${ }^{4}$ em alocar os recursos disponíveis para atender a todas as necessidades públicas, depara-se com a questão de como efetivar os direitos previstos constitucionalmente quando da ineficiência da atuação da função delegada ao Executivo e ao Legislativo.

Em outras palavras, em meio à dificuldade de atender a todas as demandas (que são praticamente ilimitadas) com um orçamento limitado, esses Poderes têm a responsabilidade de alocar os recursos de forma a garantir a eficácia e a efetividade do Texto Constitucional, competindo ao Poder Judiciário garantir (ao ser provocado para tutelar esses direitos) que essas escolhas de natureza política não fragilizem determinado direito fundamental a ponto de caracterizar uma proteção insuficiente por parte do Estado.

\footnotetext{
3 Cabe ressaltar a existência de uma corrente expressiva que entende que, em razão de o direito social ser parte dos chamados direitos fundamentais (direito à saúde, à educação, ao trabalho, etc.), acarretaria a aplicabilidade imediata prevista no artigo $5^{\circ}, \int 1^{\circ}$, da Constituição, e consequentemente não se poderia falar em normas programáticas (no sentido de dependência da atuação legislativa/reguladora). Ocorre que, considerando a eficácia limitada (necessidade de norma regulamentadora, por exemplo) e a dificuldade de se aplicarem os direitos fundamentais de maneira absoluta, ou seja, sem qualquer restrição, não se pode ignorar, no entendimento deste trabalho, não somente o conflito entre eles, mas também as condições reais para a sua perfeita aplicação, diante da complexidade e extensão que eles podem assumir. Isso não significa que se ignore a aplicabilidade imediata para os referidos direitos, nem a defesa da sua exclusão do rol de direitos fundamentais, muito menos a dependência destes da atuação legislativa, mas, sim, a observância de uma macrojustiça que envolve diversas variáveis às quais uma visão concentrada no caso concreto pode não se ater.

4 É preciso ter-se presente, contudo, que no contexto do Estado Democrático essa discricionariedade se restringe, havendo, assim, uma ampliação da vinculação dos Poderes Públicos à realização desses direitos (LEAL, 2014, p. 209).
} 
Uma vez previstos como direitos fundamentais, os direitos sociais gozam de aplicação imediata (conforme $\int 1^{\circ}$ do artigo $5^{\circ}$ da Constituição Federal), porém, o Poder Público muitas vezes frustra o direito do cidadão ao permanecer omisso quanto a seu dever prestacional, seja na garantia de direitos sociais e coletivos, seja na garantia de direitos individuais. Embora aquele esteja vinculado ao Texto Constitucional, que determina a elaboração da norma específica, não há prazo para que efetue seu dever. Mas diante da inadimplência (ou até mesmo de insuficiência da atuação) do Estado, ocorre um movimento de busca judicial pela sua concretização.

Em relação à aplicação imediata (consoante o citado dispositivo constitucional), embora algumas normas dependam de regulamentação para que se possa atingir sua plenitude (de eficácia limitada) ou existam direitos sociais garantidos por meio de normas dependentes de prestações tanto fáticas quanto normativas, ou seja, da atuação prestacional do Estado, não há que se falar que os direitos sociais permaneçam reféns da ação deste. Embora dependentes de sua atuação, esses direitos devem, sim, ser efetivados, ocorrendo, muitas vezes, a busca judicial pela sua concretização em razão da inércia estatal. Importante ressaltar os ensinamentos de Sarlet (2012, p. 316, grifo nosso) no sentido de que

[...] o dever de outorgar às normas de direitos fundamentais sua máxima eficácia e efetividade convive, por sua vez, com o dever de aplicação imediata de tais normas, razão pela qual se fala [...] no que diz com a aplicabilidade imediata, em uma regra que enuncia tal dever. Em termos pragmáticos, o que importa destacar, neste contexto, é o fato de que um direito fundamental não poderá ter a sua proteção e fruição negada pura e simplesmente por conta do argumento de que se trata de direito positivado como norma programática e de eficácia meramente limitada, pelo menos não no sentido de que o reconhecimento de uma posição subjetiva se encontra na completa dependência de uma interposição legislativa. Para que os direitos fundamentais possam ser efetivamente "trunfos contra a maioria" também é preciso que se atente [...] de que é a lei que se move no âmbito dos direitos fundamentais e não o oposto.

Ainda, o referido autor coloca que é possível compreender do Texto Constitucional tanto um dever de maximização da eficácia e efetividade das normas que tratem de direitos fundamentais quanto a regra de aplicabilidade imediata destas, do que deriva a exclusão de seu caráter meramente programático, pois elas "[...] não podem ser reduzidas à condição de normas não autoaplicáveis, no sentido de normas destituídas de qualquer eficácia ou aplicabilidade." (SARLET, 2012, p. 318). Portanto, a eficácia da lei não pode, em regra, impedir a aplicação da norma que garante o direito, pois caso esse fosse o entendimento, esvaziar-se-iam as normas a ponto de serem implementadas conforme a disposição política, em vez de uma garantia contra uma maioria.

Referente à análise realizada pelo controle jurisdicional, os recursos do Erário devem prioritariamente assegurar um mínimo de condições de existência para promover o bem-estar cobiçado pela Constituição de 1988. O poder reservado aos Poderes Executivo e Legislativo para organizar e alocar o dinheiro público de maneira autônoma, num modelo democrático pluralista, permite-lhes, por juízo de conveniência e oportunidade, certo grau de discricionariedade, contudo não exclui do 
Estado a responsabilidade do fornecimento daquelas condições e do cumprimento racional ${ }^{5}$ das prestações que lhe são atribuídas. Estas não podem ser voltadas somente para uma parcela da população amplamente representada apenas por ser a maioria do eleitorado, há a necessidade de se assegurar um mínimo de prestações que visem a dar condições básicas também às minorias (suprindo, assim, as deficiências do modelo representativo).

Assim, quando injustificadamente se revelarem ineficientes os esforços ou, ainda, for inexistente qualquer ação do Estado para a garantia dos direitos fundamentais, independente de sua dimensão (individuais, sociais, ou coletivos/difusos), como forma de guarda da Constituição, a intervenção judicial busca assegurar o seu devido cumprimento. Assim, como necessitam de políticas públicas e outras atividades prestacionais do Estado para a sua concretização, como já referido, o controle jurisdicional se aplica como instrumento que viabiliza e protege-os, possibilitando, como evidente exceção à regra, a intervenção judicial inclusive para a determinação de alocação de recursos para salvaguardar um direito fundamental que esteja sendo violado. Nesse sentido, cita-se o julgamento da ADPF n. 45 (BRASIL, 2004), no qual restou demonstrado que nos casos de abusividade governamental, diante do caráter relativo da conformação do legislador, é legítima a atuação jurisdicional para preservar a integridade e a intangibilidade do núcleo consubstanciador do mínimo existencial, reconhecendo, assim, a dimensão política da jurisdição constitucional atribuída ao STF.

Contudo, o Estado, por estar limitado em seus recursos, muitas vezes não tem condições de implantar ações suficientes para materializar plenamente todos os direitos, principalmente os de cunho social, exigindo-se dele uma atuação inteligente e responsável. Muitas vezes, a reserva do possível é suscitada argumentativamente pelo Administrador para fundamentar a sua limitação na concretização dos direitos que demandam prestações fáticas, não sendo possível exigir deste um alcance ilimitado na concretização dos direitos enunciados no corpo da Constituição. A partir do ponto em que se reconhece que as demandas de uma sociedade são intermináveis, é evidente que caberá ao Administrador a incumbência de fazer escolhas trágicas (trade-offs), obrigando-o a tornar o consumo do patrimônio público compatível com uma política que disponha do Erário de modo razoável.

Cabe ressaltar que o empecilho da reserva do possível não trata apenas da reserva orçamentária, mas da razoabilidade da pretensão como um todo. Para melhor compreender esse tema, Mânica (2010, p. 11, grifo do autor) esclarece, a partir de sua origem no julgamento promovido pelo Tribunal Constitucional alemão, em decisão conhecida como Numerus Clausus (BverfGE n. 33, S. 333), o significado da expressão "reserva do possível":

No caso, a Corte alemã analisou demanda judicial proposta por estudantes que não haviam sido admitidos em escolas de medicina de Hamburgo e Munique em face da política de limitação do número de vagas em cursos superiores adotada

\footnotetext{
5 Racional no sentido de que as circunstâncias demonstram a tentativa de máxima potencialização dos recursos financeiros e dos serviços públicos disponíveis para alcançar os objetivos previstos na Constituição (especialmente sobre direitos fundamentais). Em outras palavras, utilizar-se do aparato estatal para garantir primeiramente o básico para uma vida digna a todos e, após, maximizar ao máximo os direitos sociais (assim como os coletivos e individuais) dentro das possibilidades apresentadas, não podendo submeter a escolha da alocação dos recursos públicos para a concretização dos direitos fundamenais, por exemplo, aos interesses de uma maioria representativa ou interesses políticos/econômicos/sociais que não sejam de caráter e de interesse público.
} 
pela Alemanha em 1960. A pretensão foi fundamentada no artigo 12 da Lei Fundamental daquele Estado, segundo a qual "todos os alemães têm direito a escolher livremente sua profissão, local de trabalho e seu centro de formação".

Ao decidir a questão o Tribunal Constitucional entendeu que o direito à prestação positiva - no caso aumento do número de vagas na universidade - encontra-se sujeito à reserva do possível, no sentido daquilo que o individuo pode esperar, de maneira racional, da sociedade. Ou seja, a argumentação adotada refere-se à razoabilidade da pretensão.

As necessidades praticamente ilimitadas obrigam o Administrador a fazer essas escolhas trágicas (trade-offs), não sendo viável dispor do orçamento público para qualquer tipo de gastos. Em razão dessas escolhas, não é razoável exigir toda e qualquer prestação. Dentro de um imenso leque de opções, as escolhas políticas ganham espaço; contudo, isso não exime o Administrador de garantir as condições básicas já mencionadas, por isso a origem, na doutrina e na jurisprudência alemãs, da noção de "mínimo existencial" (LEAL, 2014, p. 207). Atualmente, graças ao forte posicionamento jurisprudencial, consoante expõe Mânica (2010, p. 12, grifo do autor), "[...] a teoria da reserva do financeiramente possivel tem sido afastada como panaceia apta a afastar a obrigatoriedade de efetivação dos direitos fundamentais sociais pelo Estado." No mesmo caminho, Galdino (2005, p. 235, grifo do autor) refere que:

A compreensão dos custos como meios de promoção dos direitos, e a observação empírica de que tais meios são insuficientes para atender a todas as demandas, leva necessariamente à conclusão de que não é propriamente a "exaustão da capacidade orçamentária" que impede a realização de um determinado direito subjetivo fundamental (embora isso também seja possível). O referido argumento usualmente presta-se a encobrir as trágicas escolhas que tenham deixado de fora do universo do possível a tutela de um determinado bem invocado na qualidade de "direito" fundamental.

O Administrador não pode se isentar de seus compromissos alegando a inviabilidade econômica de forma descomprometida, como uma escusa genérica que a tudo serve como resposta, exigido-se dele a comprovação de efetiva ausência de recursos (exaustão orçamentária). Nesse ponto, é necessário entender que a escassez orçamentária é, sim, um impedimento para a concretização dos direitos, mas deve ser analisada de forma criteriosa, questionando-se quais os recursos materiais e para onde eles estão sendo direcionados, principalmente se os investimentos estão sendo administrados de forma eficiente e razoável, que garanta as mínimas condições para a população.

Porém, como ventilado antes, essa teoria não consiste exclusivamente na análise financeira da concretização de um dado direito, mas também na razoabilidade da ação exigida do Administrador. Ressalta-se que, conforme a decisão do Tribunal Federal Constitucional Alemão que a originou, o pedido foi julgado improcedente não em razão da escassez de recursos, mas em decorrência do critério da razoabilidade da prestação requerida do Estado.

Assim, o referido julgado entendeu que o pedido de reconhecer a obrigação de garantir o ingresso no Curso de Medicina na universidade de todo aquele que assim pretendesse, ainda que houvesse recursos para tanto, estava fora dos limites do razoável. Cabe mencionar que estavam em debate o direito de liberdade de escolha da profissão e o livre acesso ao ensino superior. 
Com isso, questiona-se: como deve o magistrado distinguir o que pode ser considerado razoável exigir do Estado daquilo que não é razoável? Considerando-se que se trata de uma pergunta para a qual não há, a priori, uma resposta evidente, tratar-se-á, a seguir, como a teoria do discurso pode contribuir para a busca de uma solução adequada e racional para a pergunta lançada.

\section{0 processo judicial como discurso jurídico}

Inicialmente, é importante referir que a justificação da decisão, por meio do procedimento do discurso jurídico, mostra-se importante para a construção das decisões, pois pretende conceder racionalidade ao sistema jurídico, embora não signifique a garantia de uma única resposta correta. Conforme ensina Gavião Filho (2011, p. 144), pode ser que sejam encontradas várias respostas discursivamente possíveis e, portanto, corretas.

O discurso jurídico trata de questões práticas e da racionalidade das proposições normativas que determinam o modo de agir e de não agir, assim como se desenvolve de forma restrita ao ordenamento jurídico vigente (normas jurídicas, dogmática jurídica e decisões judiciais) e com a pretensão de correção. ${ }^{6}$ Assim, para Gavião Filho (2011, p. 150), a discussão jurídica pode ocorrer tanto pela dogmática jurídica quanto na aplicação das normas jurídicas para a produção de decisões judiciais.

No primeiro caso, trata-se de uma argumentação racional, permitindo a apresentação das melhores razões (favoráveis ou não) para justificar determinada proposição normativa. Já no segundo caso, em decorrência das limitações (formalidades e regras processuais, assim como a parcialidade dos polos da ação), entende o referido autor que ainda assim pode ser configurado como atividade comunicativa nos moldes exigidos pela teoria do discurso (GAVIÃO FILHO, 2011). Desse modo, dialogando de forma cooperativa entre as partes envolvidas, ou seja, que sejam respeitados a diversidade e os interesses contrários em disputa, sem excluir o consentimento racional e o debate cooperativo, podendo haver a contribuição com formulações de posições intersubjetivamente compartilhadas (distinção entre o objetivo da parte e a contribuição da decisão para a justiça, como propósito institucional).

Como exemplo para o que foi referido, em relação ao segundo caso, pode-se mencionar tanto as ações de controle concentrado de constitucionalidade (cujo único objeto de análise é o texto normativo abstrato) quanto as demandas (cujos fatos restam incontroversos), sendo ambos os casos voltados ao embate exclusivamente sobre matéria de Direito. Nesses exemplos, é mais fácil identificar a teoria do discurso, pois se trata de colisão de entendimentos contrapostos, visando à construção de uma proposição normativa que surte efeitos não somente entre as partes, mas também para outros juízes, juristas e a sociedade em geral.

Vale lembrar que Alexy propõe um sistema que prevê condições de prioridade, estruturas de ponderação e com prioridades prima face. Desse modo, contrapõe-se à busca de uma única resposta correta, possibilitando à decisão estabelecer relações de prioridade para os casos em concreto, por

$\overline{6}$ A pretensão de correção será abordada mais adiante. 
meio da aplicação da ponderação, por exemplo, formulando um sistema racional para a resolução dos conflitos das normas (PEDRON, 2004).

Não obstante isso, tanto os princípios quanto as regras devem ser encarados como enunciados deontológicos, portanto, buscam com a interpretação da norma aquilo que é devido. Em contrapartida, os valores apresentam enunciados teleológicos, almejando alcançar o que é bom, melhor ou preferível, sendo condicionados a uma determinada cultura. Portanto, segundo a compreensão de Alexy, a norma perde a característica de código binário para se transformar em um código gradual, enquanto a adequabilidade cede espaço para uma aplicação ponderada (balanceada) dos princípios tidos como comandos otimizáveis (OLIVEIRA, 2002, p. 88-90).

Decorrente dessa função institucional, verifica-se no discurso jurídico a pretensão de correção. Em outras palavras, uma afirmação dentro de uma discussão tem sempre a pretensão de que esta seja aceita como uma verdade, podendo ser satisfeita ou não tal ambição. Portanto, cabe referir que quando um juiz profere uma decisão (afirmação), como no caso em que estipula o que é razoável esperar do Estado na concretização de um direito social fundamental cuja norma exija uma prestação estatal, aplicando uma norma jurídica, coloca a pretensão de que a proposição normativa particular vinculante juridicamente para as partes do conflito seja correta. Assim, assume a tarefa de justificá-la e mantém a expectativa (esperança) de que a sua decisão seja aceita como correta não apenas pelas partes, mas pela comunidade como um todo. Não apenas as decisões judiciais têm tal função, mas o Direito como um todo. Ele promove pretensão de correção, por meio de normas jurídicas ou por proposições normativas singulares das decisões judiciais. Uma decisão judicial que não possua tal pretensão nada mais é do que uma decisão judicial defeituosa, imperfeita (GAVIÃO FILHO, 2011, p. 153-157).

Dessa forma, quando não for possível uma interpretação clara da norma para a aplicação da subsunção, como no caso em que o julgador deve sopesar a razoabilidade da demanda, há maior espaço para a teoria do discurso. Nesses momentos, verifica-se maior abertura necessária para o Direito, possibilitando espaço para o desenvolvimento da argumentação jurídica. Como teoria procedimental da correção prática, a teoria do discurso busca no procedimento argumentativo definido, por meio de regras, a correção de uma proposição normativa. Como regras da teoria do discurso, Gavião Filho (2011, p. 162) aponta a ausência de contradição, a clareza da linguagem, a verdade empírica, a consideração das consequências, o peso das razões, a comprovação da gênese normativa, a liberdade e a igualdade de participação no discurso.

Em relação aos erros e acertos da teoria abordada, Alexy (2010, p. 77-86) dispõe que, como modelo teórico-argumentativo, esta é caracterizada pela possibilidade de alteração das convicções normativas e fáticas dos indivíduos em virtude dos argumentos expostos no decorrer do procedimento. Dessa forma, a ideia de correção pode resultar em declarações discursivamente possíveis, corretas e, ao mesmo tempo, distintas, pois o sistema de regras, diante de uma pluralidade de casos, não determina o resultado. Contudo, para ele, "[...] as fraquezas apresentadas são, simultaneamente, sua fortidão." (ALEXY, 2010, p. 82). 
Alexy (2010), na busca de demonstrar tal afirmação, elenca como primeira dificuldade da teoria do discurso o fato de que diversas disposições normativas podem ser consideradas discursivamente possíveis quando se pressupõe a existência de uma única resposta correta para a discussão. Porém, isso não significa que toda e qualquer conclusão seja possível, o que contribui para a solução do caso ao evidenciar, diante do procedimento, quais possibilidades devem ser afastadas para a solução do caso concreto. Dessa forma, comparando com a teoria da reserva do possível, quando um julgador se depara com uma demanda que visa a uma prestação estatal manifestamente excessiva, esta pode ser facilmente rechaçada argumentativamente.

A título exemplificativo, a demanda de um serviço hospitalar, especificamente a concessão de um quarto privativo para o tratamento de uma moléstia que não justifica a sua necessidade (seja porque a doença não é transmissível, seja porque o quadro salutar não é grave a ponto de expor o demandante ao risco de infecção hospitalar), por óbvio que não é razoável exigir do Estado tal ação. Isso porque a concessão de leito hospitalar, ainda que em quarto coletivo, já é o suficiente para o atendimento ao direito fundamental disposto, diante da ausência de outra peculiaridade que justifique a sua necessidade. Desse modo, analisando-se o caso por meio do uso da proporcionalidade e de seus princípios, certamente, no caso, seria afirmativa a resposta ao questionamento acerca de se haveria outra forma, menos gravosa, de se realizar o direito - aplicando-se, assim, o segundo subprincípio da proporcionalidade, que consiste na adequação entre meios e fins, pois há outros meios menos gravosos que asseguram a realização do fim proposto.

A segunda dificuldade apontada por Alexy é a relativização sobre os participantes do discurso, que não pode iniciar do nada. Ou seja, cada convicção em particular possui o mesmo valor e se candidata de igual forma para a modificação baseada em argumentação racional. Como ponto forte, o autor coloca que o resultado do discurso é relativo na medida em que é condicionado pelas singularidades de cada participante, ao mesmo tempo que é objetivo no que se refere às regras para alcançá-lo. Desse modo, "[...] a teoria do discurso evita tanto as fraquezas de teorias morais relativistas como objetivistas." (ALEXY, 2010, p. 83).

Ressalta-se que a pretensão de correção da teoria do discurso não se trata de mero consenso alcançado por negociação, mas de uma busca pelo julgamento ideal (ou melhor, o mais próximo disso possível). Nesse sentido:

Segundo Alexy, o ponto decisivo para a teoria do discurso é que existe sempre a possibilidade de divergência entre o correto ou o objetivamente válido e o resultado de um discurso real. A razão para isso está no contexto transcendental da pretensão de correção. Os participantes do discurso são pessoas concretas, reais e historicamente situados que buscam realizar um julgamento moral correto com respeito às regras ideais da argumentação que, contudo, somente podem ser cumpridas aproximadamente. Sob essas condições, evidentemente, somente é possível se alcançar a correção tanto quanto possível. Por essa razão, então, o consenso realizado no discurso real não é constitutivo da correção ou validade objetiva. Esse seria o caso - quando, então, o consenso contaria como critério definitivo para a correção - se o discurso fosse compreendido como negociação ou decisão. Contudo, diferentemente, discurso é um procedimento argumentativo, com o que a correção está necessariamente vinculada. O critério para a correção não é o con- 
senso, mas a realização do procedimento segundo as regras do discurso. (GAVIÃO FILHO, 2011, p. 163).

Dessa forma, o terceiro ponto elencado, assinalado como o problema nuclear da teoria, é o estabelecimento e a justificação do sistema de regras, isso porque ele deve ser tão forte como possível, a fim de elevar o seu valor como decisão (ou seja, o exercício do discurso e da abertura da discussão permite uma conclusão que, no mínimo, analisou os pontos divergentes para chegar a uma decisão), assim como deve ser tão fraco como possível para encontrar ampla aprovação (no sentido de que não sejam normas perfeitas e acabadas impostas por uma divindade, pela moralidade ou predeterminadas pela natureza, mas construídas a partir de um processo racional em constante desenvolvimento). Em razão disso o sistema exige a observância de regras lógicas e da racionalidade, que, por não mostrarem nenhum conteúdo moral, encontram dificuldade para que sejam aceitas por participantes com ideias normativas diferentes (ALEXY, 2010, p. 83).

Outro aspecto é a evolução do resultado, que pode alterar com o passar do tempo, uma vez que a discussão não cessa definitivamente com a decisão, pois com o surgimento de novos argumentos acaba possibilitando a mudança de entendimento, isso porque "[...] em um discurso ideal potencialmente infinito nunca é certo se um consenso, uma vez obtido, é terminante ou definitivo." (ALEXY, 2010, p. 92).

Por fim, não há como prever todos os argumentos de possíveis participantes virtuais, ou seja, é impossível imaginar hipoteticamente todas as questões que poderiam ser suscitadas para a obtenção de um resultado definitivo. Contudo, mesmo elencando essas fragilidades da teoria do discurso, Alexy ressalta o seu valor prático.

\section{A argumentação jurídica e a ponderação: o exemplo de sua aplicação com a teoria da reserva do possível}

O discurso jurídico, como elencado anteriormente, possui a pretensão de correção e é dirigido por determinadas regras procedimentais, o que lhe distingue do discurso geral prático. Como resultado prático do discurso jurídico, encontram-se as decisões judiciais, que têm o seu valor justamente em razão da preocupação com a justificação da sua conclusão.

Assim, para constatar a racionalidade de uma decisão, esta deve estar tão bem fundamentada a ponto de que a aplicação de uma regra seja aceita pelos participantes do discurso (justificação interna), assim como seja externamente acolhida pela racionalidade dos procedimentos adotados para a justificação das premissas. Disso se extrai que quanto maior o número de conexões realizadas para alcançar coerência com o ordenamento jurídico vigente (leis ou outras decisões judiciais), maior será o grau de fundamentação das proposições alcançadas. Desse modo, é possível afirmar que "[...] a medida de coerência é dada pelo grau de critérios de coerência que são cumpridos." (GAVIÃO FILHO, 2011, p. 167).

Outrossim, a argumentação deve ser consistente, ou seja, livre de contradições entre as diversas proposições que fundamentam a decisão. Do mesmo modo, a totalidade das preposições 
deve ser coerente, o que significa que devem fazer sentido como um todo. Assim, para a construção de uma decisão coerente, necessariamente devem ser atendidos os critérios de coerência, quais sejam: propriedades da estrutura da fundamentação; propriedades dos conceitos empregados; e, propriedades do âmbito do objeto, de uma teoria ou de um sistema de proposições (GAVIÃO FILHO, 2011, p. 179-180).

A justificação argumentativa interna das decisões decorre do silogismo, o que implica dizer que de uma forma ou de outra a subsunção sempre estará presente. A partir do momento em que se tem duas premissas consideradas válidas, pode-se buscar uma conclusão lógica, uma vez que a sua verdade está condicionada à verdade das premissas relacionadas. Ou seja, se o Estado tem o dever de garantir os direitos fundamentais e se os direitos sociais também são direitos fundamentais, logo, o Estado tem o dever de garantir os direitos sociais.

Dessa forma, o argumento dedutivo visa justamente esclarecer o conteúdo das premissas, possibilitando a aplicação da subsunção. Portanto, a justificação interna tem como objetivo a universalidade das premissas levantadas, aplicando-as a todos os casos semelhantes, encadeadas e livre de contradições. Contudo, essa justificação interna é facilmente aplicada para os casos fáceis (easy cases), enquanto para alguns fatos isolados pode apresentar-se de maneira mais complexa e, quem sabe, insuficiente para a determinação da conclusão da decisão judicial (hard cases).

Nesse mesmo sentido, Barcellos (2008, p. 55) refere a ponderação como a técnica própria para os hard cases, quando o simples raciocínio da subsunção não é adequado para resolver a aplicação da norma ao fato. Isso se afirma em razão de que esses casos envolvem diversas premissas maiores igualmente válidas e de mesma hierarquia (conflitos normativos), indicando para cada um soluções normativas diversas e até mesmo contraditórias. Desse modo, a subsunção por si só não possui instrumentos suficientes para produzir uma conclusão que abarque em seu processo de construção todos os elementos normativos pertinentes, pois sua lógica se limita a isolar uma única norma para o caso.

Igualmente, a justificação externa encontra a mesma dificuldade diante das contradições possíveis, contudo, em vez de justificar com a própria premissa a resolução do caso concreto, para a justificação externa deve o julgador fundamentar a escolha da premissa utilizada. Em outras palavras, o ponto específico dessa justificação racionalmente discursiva está na escolha e na construção das premissas que integram a fundamentação da proposição defendida de forma concreta em uma decisão judicial (GAVIÃO FILHO, 2011, p. 190).

Decorrente desses fatos, verifica-se que a norma pode admitir mais de uma interpretação, dificultando uma afirmação com plena segurança quando ocorrer o que Hart chama de textura aberta (open texture), o que Alexy denomina espaços semânticos (semantischen Spielraum), e que abrangem a ambiguidade, a vagueza e a abertura valorativa, conforme esclarecimentos do escritor Gavião Filho (2011, p. 174). O referido autor segue dizendo:

Contudo, nos casos de espaços semânticos, a forma simples de justificação interna se mostra insuficiente. Algumas disposições constitucionais e infraconstitucionais do ordenamento jurídico servem para indicar a correção dessa formulação. A disposição do art. 196, caput, da Constituição Federal, diz que a saúde é um direito 
de todos e dever do Estado, garantido mediante políticas sociais e econômicas que visem à redução do risco de doença e de outros agravos e ao acesso universal e igualitário às ações e serviços para a sua promoção, proteção e recuperação. A partir dessa normalização constitucional, coloca-se a questão sobre a possibilidade de um indivíduo, afirmando-se titular do direito fundamental à saúde, deduzir contra o Estado uma pretensão a uma prestação material consistente no fornecimento periódico de medicamentos ou a realização de uma intervenção cirúrgica. O que deve ser respondido é se a palavra "saúde" pode ser interpretada de modo a configurar posição fundamental jurídica definitiva a prestações materiais específicas, consistente no fornecimento de um medicamento determinado ou na realização de um determinado procedimento cirúrgico. Uma resposta positiva, sem muitas dúvidas, pode ser encontrada se o caso é de uma pessoa que se encontra em estado tal que um determinado medicamento ou procedimento cirúrgico é necessário para assegurar a sua vida ou condições de saúde mínimas. Uma mesma resposta positiva livre de dúvida talvez não pode ser alcançada, pelo menos sem premissas adicionais, se caso é de uma pessoa que pretende, com fundamento na disposição constitucional, a realização de uma cirurgia estética sob a alegação de que tal é necessário para a saúde mental e psicológica. (GAVIÃO FILHO, 2011, p. 175 , grifo do autor).

Assim, quando as premissas são abstratas, como no caso citado, deve-se estabelecer, de forma racional, uma ordem de primazia (os a priori argumentativos), o que Alexy (2011, p. 90) abordou com os "mandamentos de otimização", que abordam a colisão de princípios de forma a cumpri-los em diferentes graus, diante das condições do caso concreto e das possibilidades jurídicas. Assim, apenas quando se deparar com um caso concreto será possível ao julgador realizar essa mensuração de primazia entre os dispositivos conflitantes. Tal exercício contribui com a coerência da decisão e do sistema em que está inserida.

Nesse espaço de colisão entre tais normas, com o intuito de manter uma coerência na argumentação jurídica realizada de forma discursiva, importante se faz a demonstração da ponderação aplicada sobre o caso específico. Porém, antes de realizar os passos para a sua construção, impende referir algumas características básicas da ponderação.

Fundamentalmente, cabe referir que a otimização está diretamente ligada ao princípio da proporcionalidade, e subdivide em três subprincípios: idoneidade (que para Alexy seria adequação), necessidade e proporcionalidade, em sentido estrito (GAVIÃO FILHO, 2011, p. 239). Esses princípios formadores do princípio da proporcionalidade devem ser satisfeitos ou não, ou seja, não são relativizados.

Desses três subprincípios, os primeiros (máxima da adequação e máxima da necessidade) decorrem da natureza dos princípios como mandamentos de otimização em face das possibilidades fáticas. Já a máxima da proporcionalidade em sentido estrito decorre do fato de serem os princípios mandamentos de otimização em face das possibilidades jurídicas (ALEXY, 2011, p. 118).

O primeiro (adequação) significa que para restar satisfeito é necessário que uma violação de qualquer direito fundamental, promovida por determinada intervenção, seja em prol da realização de outro direito fundamental ou bem jurídico coletivo protegido constitucionalmente (finalidade da medida interventiva). Assim, as premissas empíricas, fundadas em conhecimentos científicos 
e convicções sociais, devem ser examinadas a ponto de somente caracterizar a adequação quando sua intervenção for uma medida necessária para atender ao fim perseguido.

Para demonstrar a adequação, Alexy (2011, p. 589) cita o exemplo do cabeleireiro que mantinha em seu estabelecimento uma máquina automática para vender cigarros. $\bigcirc$ Poder Público, constatando o fato, exigia, por meio de uma lei, permissão para a venda, que exigia a "necessária expertise" para o comércio desse produto. Ocorre que tal medida (exigência) violava o direito de liberdade profissional do cabeleireiro, bem como se mostrou inadequada para proteger os direitos do consumidor contra prejuízos à sua saúde ou contra prejuízos econômicos. Assim, a adequação se constata na medida em que a intervenção não é capaz de satisfazer a finalidade perseguida.

O segundo (necessidade) implica a escolha entre todas as possibilidades adequadas (ou idôneas) daquela que, para a concretização da finalidade da medida interventiva, provocar a menos agressiva ao direito fundamental relativizado. Assim, diante de um estudo comparativo das diversas alternativas, deve-se optar por aquela que satisfaça a idoneidade da medida tanto quanto cause a menor lesão possível, utilizando-se, para tanto, de critérios quantitativos, qualitativos e probabilísticos (GAVIÃO FILHO, 2011).

Mantendo o exemplo do conflito entre o direito à liberdade profissional e a proteção do consumidor, Alexy (2011, p. 590) ilustra a análise com o caso em que uma portaria proibisse a comercialização de um produto (chocolate em pó) que continha em seu conteúdo essencialmente flocos de arroz, não sendo genuinamente de chocolate. Ocorre que a proibição (medida interventiva) é adequada para a finalidade de proteger o consumidor de se equivocar sobre o produto que está adquirindo, mas não é a medida (ou uma das medidas) menos danosa ao direito de liberdade profissional. Isso porque a simples obrigatoriedade de informação no rótulo da composição do produto seria suficiente para proteger o consumidor do equívoco, sem prejudicar o direito do comerciante.

Nesse sentido, o doutrinador alemão Alexy (2011, p. 591) esclarece que o legislador que persegue um objetivo escolhido para a proteção de um direito "[...] pode adotar apenas o meio mais suave, ou o meio igualmente suave ou um meio ainda mais suave. Isso não é nenhuma otimização em direção a algum ponto máximo, mas apenas a vedação a sacrifícios desnecessários."

Diante da adoção desse método de ponderação, o meio escolhido não será necessário se o objetivo puder ser alcançado por meio de medida(s) que seja(m) ao mesmo tempo adequada(s) e menos onerosa(s). Frisa-se, adequação e necessidade não possuem o mesmo peso/relevância nessa fórmula, pois o meio necessário deve ser adequado ao caso, enquanto nem tudo o que for adequado é necessário, consoante ensinamentos de Mendes e Branco (2012, p. 259, grifo do autor), que explicam:

O subprincípio da adequação (Geeignetheit) exige que as medidas interventivas adotadas se mostrem aptas a atingir os objetivos pretendidos. A Corte Constitucional examina se o meio é "simplesmente inadequado" (schlechthin ungeeignet), "objetivamente inadequado" (objetktiv ungeeingnet), "manifestamente inadequado ou desnecessário" (offenbar ungeeignet oder unnötig), "fundamentalmente inadequado" (grudsätzlich ungeeignet), ou "se com sua utilização o resultado pretendido pode ser estimulado" (ob mit seiner Hilfe der gewunschte Erfolg gefördet werden kann). O subprincípio da necessidade (Notwendigkeit oder Erforderlichkeit) significa que nenhum meio menos gravoso para o indivíduo revelar-se-ia igualmente eficaz na consecução dos objetivos pretendidos. 
Por fim, Mendes e Branco (2012, p. 259) compreendem que o terceiro passo, da proporcionalidade em sentido estrito, assume o papel de "controle de sintonia fina" (Stimmigkeitskontrolle), para apontar a solução encontrada ou a necessidade de sua revisão.

Assim, passa-se ao terceiro subprincípio, da proporcionalidade em sentido estrito, que diferente dos primeiros não está atrelado a questões fáticas, mas a questões jurídicas, identificando-se com a própria ponderação. Significa que a importância do cumprimento de um princípio implica necessariamente a relação inversa com o princípio violado. Ou seja, busca-se, diante das características que envolvem o caso concreto, qual dos dispositivos colidentes deve prevalecer sobre o outro (GAVIÃO FILHO, 2011, p. 249).

Esse terceiro passo para a análise da proporcionalidade considera que "[...] quanto maior for o grau de não satisfação ou de afetação de um princípio, tanto maior terá que ser a importância da satisfação do outro." (ALEXY, 2011, p. 593). Para tanto, o doutrinador alemão divide essa fase em três passos.

O primeiro trata da avaliação do grau de não satisfação ou afetação de um dos princípios. No segundo, analisa-se o grau de importânica da satisfação do princípio envolvido colidente com o primeiro. Já o terceiro e último passo aborda a comparação entre a importância da satisfação do segundo princípio com a afetação ou a não satisfação do primeiro, visto que dessa análise se compreende se a intervenção justifica a redução do gozo do direito prejudicado (ALEXY, 2011, p. 594).

Verifica-se que não há como fugir de um mínimo de subjetividade do julgador, tanto que a concepção da ponderação de Alexy sofre críticas de doutrinadores como Habermas e Böckenförde. Para rebater a essas críticas, aquele menciona que o grau de satisfação ("pequeno", "médio" e "alto") e de afetação ("leve", "moderado" e "sério") pode ser medido pelo modelo triádico (ALEXY, 2011, p. 595).

Contudo, a dificuldade reside em como a atribuição da análise subjetiva para a intervenção se encontra passível de controle racionalmente intersubjetivo. Não obstante isso, questiona-se a legitimidade dos magistrados ao decidirem quanto à intensidade das intervenções e realização de direitos fundamentais sem o comprometimento da reserva de competência dos três Poderes. Essa crítica é corroborada pelo argumento da irracionalidade e subjetividade da ponderação, que se encontra fundada em quatro pontos, quais sejam: " [...] i) falta de ponto de referência jurídico para apoiar a aplicação da ponderação; ii) falta de clareza conceitual; iii) prevalência do modelo da 'justiça do caso concreto'; iv) incomensurabilidade." (GAVIÃO FILHO, 2011, p. 252, grifo do autor).

O primeiro decorre da ausência de qualquer obrigação do magistrado em fundamentar a aplicação da ponderação com critérios objetivos. $O$ segundo demonstra a amplitude da expressão, concedendo ao julgador grande margem de subjetividade. $O$ terceiro aponta a falta de segurança jurídica diante de decisões particulares que não necessariamente julgam sob os mesmos critérios, justamente em razão da subjetividade referida. Por fim, o quarto deriva da falta de um sistema objetivo para calcular os diferentes graus de vantagens e desvantagens entre direitos fundamentais colidentes (GAVIÃO FILHO, 2011). 
No entanto, todos esses problemas na verdade evidenciam não um defeito no procedimento da ponderação em si, mas na forma como ela é aplicada. Nesse sentido, Gavião Filho (2011, p. 260) explica que:

$\mathrm{Na}$ grande maioria dos casos, as decisões judiciais se limitam ao estabelecimento da relação de prevalência condicionada às circunstâncias do caso concreto como se esse fosse o único passo necessário. Como esse não é o caso, os saltos lógicos são inevitáveis. A proposição da conclusão do argumento não resulta logicamente das premissas que são apresentadas para sua fundamentação. $O$ resultado é que não se pode falar seriamente em uma fundamentação. As premissas permanecem, para sempre, ocultas. Muito dificilmente os passos intermediários são explicados. Nesses casos, a proposição normativa concreta parece ser um resultado intuitivo.

Assim, torna-se evidente a necessidade e a importância da demonstração da construção do entendimento alcançado para a prolação da decisão judicial. Mesmo quando se utiliza o critério da proporcionalidade para sopesar o conflito entre dois ou mais direitos fundamentais, sua demonstração é essencial, sob pena de possibilitar que o controle jurisdicional resulte em uma análise subjetiva do caso concreto.

Desse modo, por meio da argumentação prática e da jurídica, expõe-se um procedimento racional para o alcance do resultado dentro das regras do discurso. Para a realização dessa incumbência, a justificação racional deve preencher todos os passos e suas exigências. Para tanto, a investigação dos graus de intensidade de intervenção e de importância de realização de determinados princípios colidentes, uma vez comparados, mostra-se essencial para o exercício da ponderação.

Dessa forma, identificam-se os três passos propostos por Alexy já mencionados. Justificando cada passo de maneira individual, bem como se utilizando de premissas e conclusões devidamente estruturadas, concede-se ao procedimento à racionalidade exigida para evitar os saltos lógicos anteriormente mencionados.

Para uma melhor demonstração dessa construção discursiva, será tratado um caso hipotético no qual o magistrado deve decidir sobre uma demanda em que é acionado para garantir o acesso à creche para uma criança de cinco anos. Paralelamente, será demonstrado o caso de uma demanda que visa ao acesso ao ensino superior por estudante que pleiteia uma vaga em universidade pública, mas que não obteve uma vaga por meio tradicional de ingresso realizado com a prestação de vestibular.?

Inicialmente, impende referir que ambos os casos demonstram a adequação de uma possível medida interventiva que garanta o acesso à educação, em razão de serem meios de se concretizar o direito fundamental à educação. Igualmente, pode-se entendê-las como necessárias para a garantia desse direito, diante da necessidade do acesso ao ensino. Assim, passa-se ao terceiro momento da análise, qual seja, a proporcionalidade em sentido estrito.

Como primeiro passo, tem-se a verificação da intensidade da intervenção. Significa que se deve investigar uma grandeza para a aferição de determinados graus na ponderação, abordando tan-

\footnotetext{
7 Por não se tratar do objeto do estudo do presente trabalho, não será possível trabalhar todas as premissas possíveis de se levantar para os casos, apenas se busca uma ilustração do procedimento esperado para a demonstração da ponderação nos referidos casos.
} 
to o peso da intervenção no princípio de forma abstrata quanto considerando o máximo de circunstâncias do caso relevantes à decisão para buscar o peso da intervenção no caso concreto. Portanto, diante da distinção da grandeza abstrata da intervenção em um princípio e da grandeza concreta, pode-se alcançar a real implicação dessa intervenção no princípio relativizado.

Diante dessa regra, pode-se considerar que nos casos hipotéticos mencionados (acesso à creche e acesso ao ensino superior) ocorreria a intervenção ao princípio da separação de Poderes, uma vez que as demandas versam sobre políticas públicas referentes ao acesso ao ensino. Igualmente, afetaria ao princípio da discricionariedade do administrador público. Atendo-se a esses fatos, pode-se afirmar que, de forma abstrata, a intervenção nos referidos conceitos ocorre de forma leve, ao passo que o magistrado apenas garante algo previsto já por meio de políticas públicas, enquanto que seria médio se houvesse a determinação para garantir o custeio, e grave, em caso de criação da política pública para a garantia do direito demandado.

Analisando os exemplos citados, constata-se que a Constituição e o ordenamento jurídico garantem o acesso à educação básica, existindo atualmente todo um sistema que visa à proteção da educação infantil como uma prerrogativa constitucional indisponível, a qual exige do Estado a obrigação constitucional de criar condições objetivas que possibilitem esse acesso (artigo 208, IV, da Constituição). Não obstante a norma constitucional, há, ainda, artigos infraconstitucionais que reforçam esse dever, como o artigo 4 ${ }^{\circ}$, inciso I, e o artigo 5º da Lei n. 9.394/1996 (Lei de Diretrizes e Bases da Educação Nacional). Já o acesso ao ensino superior acaba não tendo o mesmo amparo, no sentido de exigir-se do Estado essa prestação de forma universal, uma vez que existem programas (Prouni e universidades públicas, por exemplo) que possuem um processo de inserção no ensino superior por meio da realização de provas seletivas.

Portanto, pode-se dizer que a intervenção aos princípios mencionados é, respectivamente, leve e média, considerando-se o disposto anteriormente. Conclui-se, assim, o primeiro passo.

Posteriormente, na investigação da importância da realização de determinado princípio, na verificação e justificação do seu grau, impõe-se a análise das circunstâncias da situação concreta. Por estarmos diante de colisão de princípios, para a análise dessa etapa se verificam as repercussões que a omissão ou a não efetivação da medida interveniente sobre a realização ou cumprimento desse princípio acarretam.

Dessa forma, o direito à educação, presente em ambos os casos, é assegurado constitucionalmente (artigos $6^{\circ}$ e 205 da Constituição). Outrossim, não há dúvidas que a inaceitável omissão governamental no fornecimento do ensino básico está apta a frustrar injustamente o direito fundamental de toda e qualquer criança. Ainda, é possível configurar tal prestação como a garantia do mínimo existencial para assegurar condições mínimas de dignidade ao ser que se encontra em processo de desenvolvimento.

Entretanto, isso não é possível afirmar quanto ao ingresso ao ensino superior, visto que a omissão do Estado (se considerar de modo absoluto o direito à educação previsto na Constituição) não configura a mesma proporção na lesão do direito do demandante. Não obstante, ressalta-se que o Estado ainda proporciona o acesso ao ensino superior, contudo, este é limitado a determinado nú- 
mero de vagas, concedidas pelas diversas formas de políticas públicas já estabelecidas (novamente, citam-se os exemplos do Prouni e das universidades públicas).

Portanto, pode-se dizer que a importância da realização ou cumprimento do princípio que garante o acesso à educação é, respectivamente, grave e leve, considerando a argumentação exposta. Passa-se, por fim, ao terceiro passo.

A relação entre os graus constatados consiste no último passo, quando são postos em comparação de tal modo que seja respondido se a importância de um princípio justifica a intensidade de intervenção, concluindo-se, desse modo, uma relação de prevalência. A possibilidade de realizar essa comparação afasta a objeção da incomensurabilidade referida anteriormente, pois demonstra um processo valorativo para a realização da ponderação. Da mesma forma, como o esgotamento da análise do maior número de premissas possível para o caso concreto rechaça os argumentos da falta de ponto de referência jurídico e da falta de clareza conceitual, o que implica, igualmente, uma decisão que esclarece como ponderou o conflito instaurado, possibilitando o uso do mesmo raciocínio para casos semelhantes e afastando a prevalência do modelo da "justiça do caso concreto".

Cabe referir, ainda, que seguindo os ensinamentos de Gavião Filho (2011, p. 273-274), dois conceitos contribuem com a comensurabilidade da relação entre as duas verificações: o primeiro é o ponto de vista uniforme dado pelo "ponto de vista da Constituição" e o segundo é a escala capaz de proporcionar os graus para a avaliação das perdas e ganhos jurídico-fundamentais, denominada "escala triádica".

Portanto, para os exemplos aqui abordados, pode-se aduzir que a importância (grave) de garantir o acesso ao ensino básico, no primeiro caso, é suficiente para justificar a intervenção (leve) na discricionariedade e na separação dos Poderes para a concretização do direito fundamental. Já a importância (leve), no segundo caso, não é suficiente para justificar a intervenção (média) demandada.

Com isso, atendido o subprincípio da proporcionalidade em sentido estrito diante da ponderação realizada, o caso da demanda pela vaga em instituição de ensino básico também atende ao requisito da adequação (pois há uma finalidade da medida interventiva que visa assegurar um direito fundamental: a educação). Igualmente, satisfaz o requisito da necessidade, pois a decisão profere uma determinação em prol da escolha entre todas as possibilidades idôneas daquela que, para a concretização da finalidade da medida interventiva, provoca a menos agressiva ao direito fundamental relativizado, ou seja, determina que o Estado matricule a criança.

Atendendo aos critérios da proporcionalidade, pode-se afirmar que a medida é razoavelmente exigível do Estado. No mesmo sentido, não havendo a comprovação do exaurimento dos cofres públicos para arcar com a decisão, afastam-se as objeções previstas pela teoria da reserva do possível que poderiam inviabilizar a concessão pela via judicial da demanda pleiteada.

Já para o segundo caso exemplificativo, ainda que houvesse tal reserva orçamentária, não seria razoável exigir do Estado a referida prestação. Isso porque se verificou, com base nos argumentos lançados, que não traria como benefício algo significativo e que fosse necessário se comparado proporcionalmente com o tipo de intervenção que seria exigido para o caso. 
Portanto, verifica-se, em relação a toda a construção discursiva, ainda que de forma limitada no presente artigo, que a decisão judicial deve atender à devida fundamentação de seu conteúdo. Contudo, infelizmente, tal procedimento não é frequentemente adotado pelos tribunais e juízes brasileiros, que muitas vezes adotam os saltos lógicos (ausência da devida argumentação jurídica) no momento de esclarecer seus juízos de proporcionalidade, o que pode ser encarado pelos demais participantes do discurso como espaço para a subjetividade do magistrado.

\section{Conclusão}

Perante todo o exposto, verifica-se que a teoria do discurso contribui de forma objetiva para a produção de decisões judiciais, uma vez que não apenas estabelece determinadas regras para a sua conclusão como concede maior racionalidade para o resultado prático. Outrossim, restou comprovado como a argumentação jurídica e o procedimento da ponderação, quando devidamente demonstrados pela sentença/acórdão, são capazes de afastar as críticas de subjetividade e a sensação de insegurança jurídica nos casos que tratam dos mencionados espaços semânticos ou textura aberta.

Demonstrou-se, de igual modo, que o critério de razoabilidade pode ser tão significativo como o orçamentário (ambos da teoria da reserva do possível) para a objeção ou concessão de determinada demanda judicial, em especial nos casos em que se objetiva a proteção aos direitos fundamentais. Assim como restou exemplificado o passo a passo de como o aludido critério da razoabilidade deve ser construído, diante da teoria do discurso, da argumentação jurídica e da ponderação, no processo de fundamentação da decisão judicial e na compreensão de seu papel na garantia dos direitos fundamentais.

\section{Referências}

ALEXY, Robert. Direito, razão, discurso: estudos para a filosofia do direito. Tradução Luís Afonso Heck. Porto Alegre: Livraria do Advogado, 2010.

ALEXY, Robert. Teoria dos direitos fundamentais. Tradução Virgílio Afonso da Silva. 2. ed. São Paulo: Malheiros, 2011.

ÁVILA, Humberto Bergmann. A distinção entre princípios e regras e a redefinição do dever de proporcionalidade. Revista de Direito Administrativa, n. 215, 1999.

BARCELLOS, Ana Paula de. Alguns parâmetros normativos para a poderação constitucional. In: BARROSO, Luís Roberto (Org.). A Nova Interpretação Constitucional: ponderação, direitos fundamentais e relações privadas. 3. ed. Rio de Janeiro: Renovar, 2008.

BRASIL. Supremo Tribunal Federal. Arguição de Descumprimento de Preceito Fundamental n. 45. Relator: Ministro Celso de Mello. Julgamento em 29 abr. 2004. Diário da Justiça da União, Brasília, DF, 04 maio 2004. Disponível em: <http://www.stf.jus.br>. Acesso em: 03 ago. 2015. 
CAMARGO, Manuela Oliveira. Proporcionalidade e razoabilidade na jurisprudência do Supremo Tribunal Federal: os casos de conflitos entre princípios da Ordem Econômica. Sociedade Brasileira de Direito Público, 2005. Disponível em: <http://www.sbdp.org.br/ arquivos/monografia/59_Manuela\%200liveira\%20Camargo.pdf>. Acesso em: 09 set. 2015.

GALDINO, Flávio. Introdução à Teoria dos Custos dos Direitos: direitos não nascem em árvores. Rio de Janeiro: Lumen Juris, 2005.

GAVIÃO FILHO, Anízio Pires. Colisão de direitos fundamentais, argumentação e ponderação. Porto Alegre: Livraria do Advogado, 2011.

LEAL, Mônia Clarissa Hennig. A dignidade humana como critério para o controle jurisdicional de políticas públicas: análise crítica da atuação do Supremo Tribunal Federal brasileiro. In: COSTA, Marli Marlene Moraes da; LEAL, Mônia Clarissa Hennig. Direitos Sociais e Políticas Públicas: desafios contemporâneos. Santa Cruz do Sul: Edunisc, 2014. Tomo 14.

MÂNICA, Fernando Borges. Teoria da Reserva do Possível: direitos fundamentais a prestações e a intervenção do Poder Judiciário na implementação de políticas públicas. Revista Eletrônica sobre a Reforma do Estado, Salvador, n. 21, mar./maio 2010.

MENDES, Gilmar Ferreira; BRANCO, Paulo Gustavo Gonet. Curso de Direito Constitucional. 7. ed. rev. e atual. São Paulo: Saraiva, 2012.

OLIVEIRA, Marcelo Andrade Cattoni de. Direito Constitucional. Belo Horizonte: Mandamentos, 2002.

PEDRON, Flávio Quinaud. Algumas considerações sobre a interpretação de Robert Alexy sobre a tese da única resposta correta de Ronald Dworkin. Âmbito Jurídico, Rio Grande, v. 7, n. 19, nov. 2004. Disponível em: <http://www.ambito-juridico.com.br/site/index.php?n_link=revista_artigos_leitura\&artigo_id=4999>. Acesso em: 10 set. 2015.

SARLET, Ingo Wolfgang. Teoria Geral dos Direitos Fundamentais. In: SARLET, Ingo Wolfgang; MARINONI, Luiz Guilherme; MITIDIERO, Daniel. Curso de direito constitucional. São Paulo: Revista dos Tribunais, 2012.

SILVA, Luís Virgílio Afonso da. O proporcional e o Razoável. Revista dos Tribunais, n. 798, 2002. Disponível em: <http://www.sbdp.org.br/arquivos/material/69_SILVA, \%20Virgilio\%20Afonso\%20da\%20-\%200\%20proporcional\%20e\%20o\%20razoavel.pdf >. Acesso em: 09 set. 2015. 
